\title{
Review of United States Data on Neoplasms in
}

\section{Rheumatoid Arthritis}

\author{
C. WILLIAM CASTOR, M.D. \\ FRANCES E. BULL, M.D. \\ Ann Arbor, Michigan
}

Relatively sparse literature developed during the past $\mathbf{3 0}$ years that sought to characterize the relationship of rheumatoid arthritis to neoplasms. The past decade has seen added concern over possible oncogenic effects of cytotoxic agents now used to manage some patients with rheumatoid arthritis. Acquisition of unambiguous data is complicated by the fact that the cumulative incidence of cancer in the general population exceeds 30 percent, and that most studies have insufficient patient numbers, duration follow-up, and attention to age, sex, race, or known etiologic agents. Thus, it is not surprising to find reports that cancer incidence is high, low, or unchanged in rheumatoid arthritis. Although equally ambiguous data were accumulated concerning potential neoplasm-inducing effects of cytotoxic drugs, concern is justified in relation to increased frequency of bladder cancer after cyclophosphamide and acute leukemia following alkylating agents.

The practice of administering cytotoxic drugs for the management of active rheumatoid arthritis unresponsive to conservative management or conventional forms of remittive therapy has been attended by increasing concern over the possibility that this form of therapy increases the frequency of malignancy in the rheumatoid patient population. Interest in this problem has been fueled by well-controlled studies describing the oncogenic properties of cyclophosphamide in NZB/NZW mice [1] in addition to many anecdotal reports describing development of neoplasms in patients with rheumatoid arthritis following cytotoxic therapy. An essential component in the data base needed to evaluate the relative risk of using cytotoxic agents in nonlethal diseases, such as rheumatoid arthritis, includes a clear perception of the "basal rate" or neoplasm development that might be anticipated in a population of patients with rheumatoid arthritis not treated with cytotoxic agents. Such information is essential to the unambiguous interpretation of outcomes related to neoplasms occurring in patients receiving cytotoxic agents. The frequent occurrence of circulating immune complexes in rheumatoid arthritis and neoplastic diseases is well recognized and has been extensively reviewed [2,3].

In rheumatoid arthritis, the immune complexes may play a pathogenetic role in the ongoing tissue destruction caused by the inflammatory process. In neoplasms, circulating immune complexes appear to reflect tumor growth and dissemination. The precise role(s) of immune complexes in the course of neoplastic diseases is yet unclear. Although a polyarthritis, superficially resembling rheumatoid arthritis, has been described as an early manifestation of various malignancies, a careful study of one case failed to detect immune complex deposition in the synovial membrane [4]. 


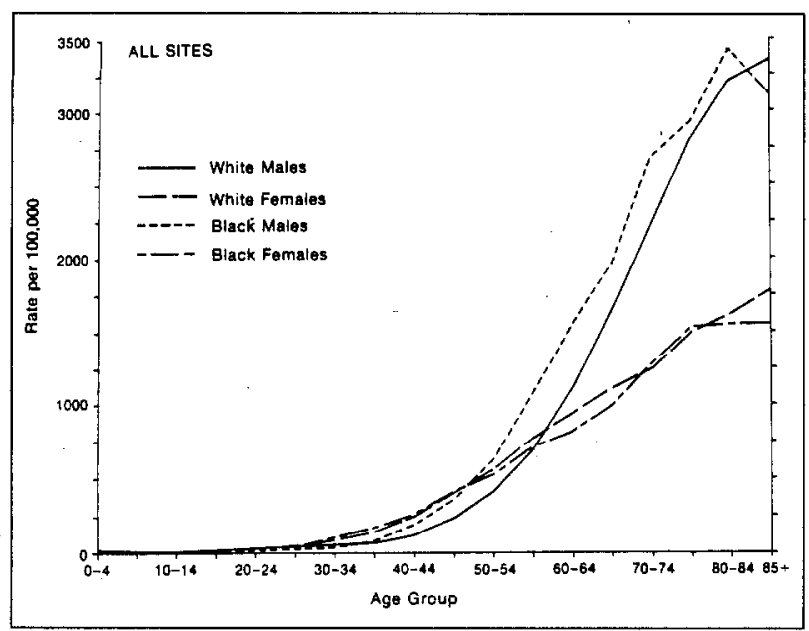

Figure 1. Average annual age-specific incidence rates per 100,000 population by race and sex, SEER Program, all areas combined, 1973-1977. (Reprinted with permission from [5].)

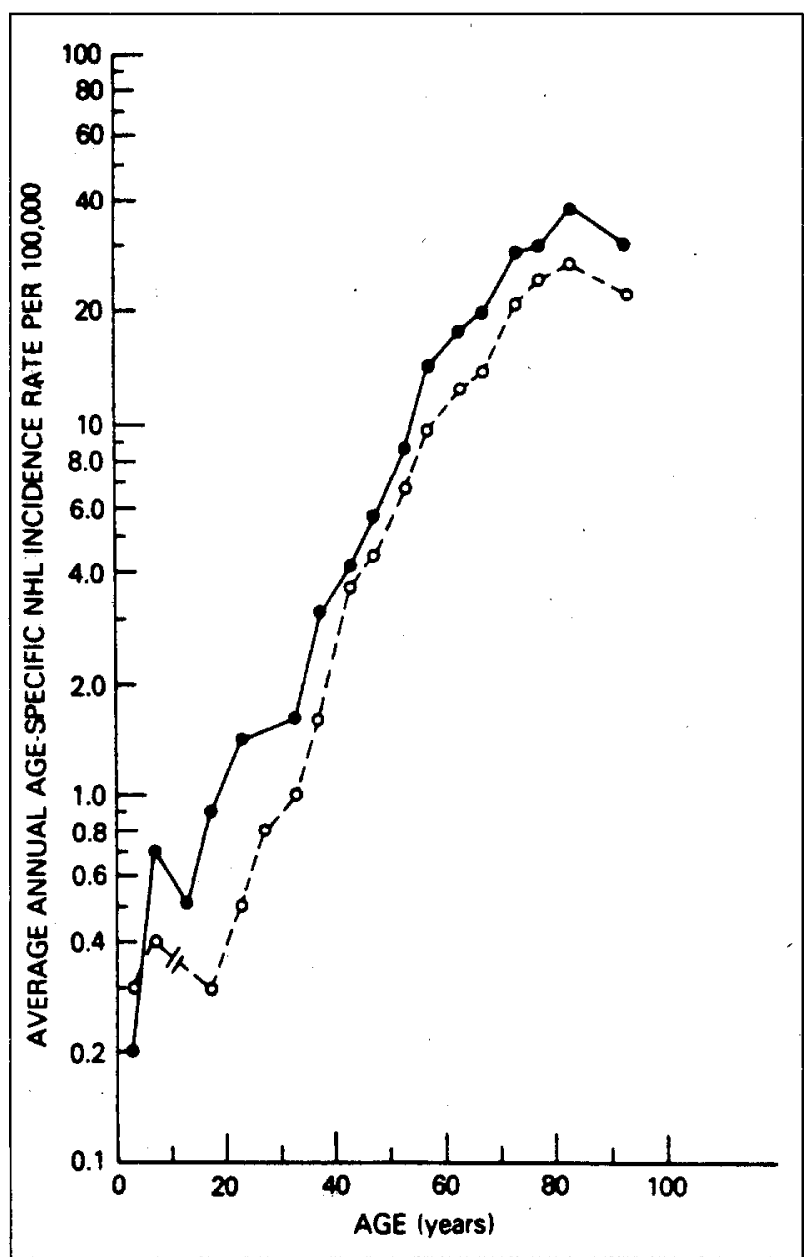

Figure 2. Average annual age-specific incidence rates per 100,000 population among white males (solid circles) and white females (open circles) in the United States. (Reprinted with permission from [6].)

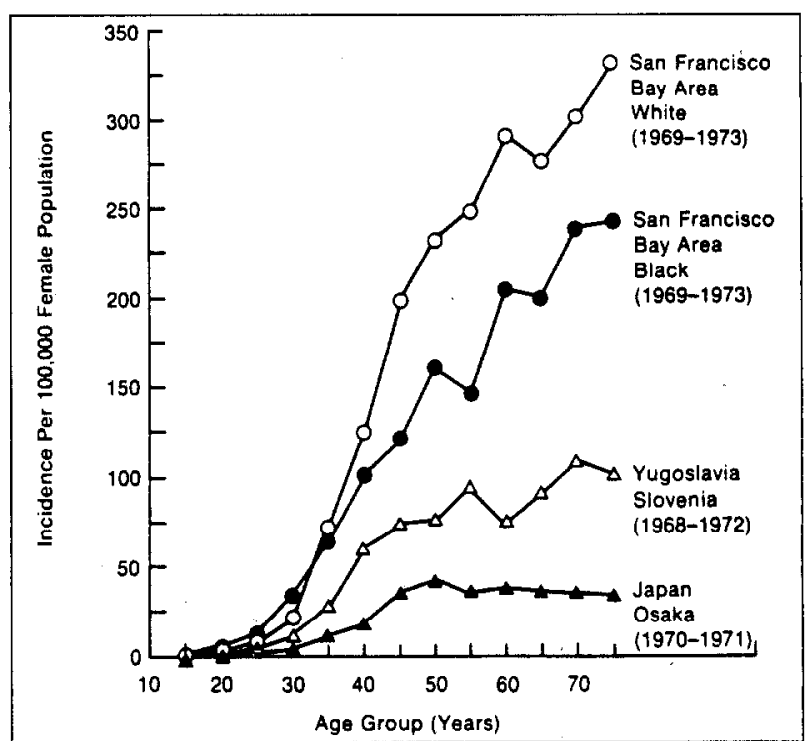

Figure 3. Age-specific incidence rates for female breast cancer in four population groups. (Reprinted with permission from [7].)

Epidemiologic studies suggest that rheumatoid arthritis affects about 1 percent of the population, and although the disease may appear at any age, the peak ages of onset include the decade from age 35 to 45 . Showing a change in the frequency of neoplasms occurring in such a population of patients with rheumatoid arthritis must take into account the high cumulative frequency of neoplasms in the general population, in which the cumulative incidence up to age 74 is approximately 26 percent in females in the United States, and 35 percent in males. As one can see in Figure 1, the age-specific incidence rates for neoplasms do not describe a linear course beginning with birth. Instead, the incidence of neoplasms begins an exponential ascent at about the age when patients with rheumatoid arthritis begin to accumulate. To further compound the problem, it is apparent that the exponents are not the same for males and females [5]. From this curve, one might anticipate that careful follow-up of women beginning at age 50 would disclose a cumulative incidence of about 3.3 percent after five years, 8.8 percent after 10 years, and 14.4 percent after 15 years. Some neoplasms of special concern to the present discussion show an age-specific incidence curve unlike the "all sites" curve in Figure 1. Non-Hodgkin's lymphoma (Figure 2) has an age-specific incidence rate starting in the first decade of life and rising dramatically in linear fashion over the usual life span. Between age 40 and 60 , the age-specific incidence increases from three to 15 per 100,000 [6]. Not only is it important to control for age and sex, but, as shown in Figure 3, with particular tumor types-in this case breast cancer-racial, ethnic, and possibly dietary or environmental factors may contribute significantly to the age-specific incidence of neoplasms [7]. 
Compilation of data related to the association of rheumatoid arthritis and neoplasms will necessarily be restricted to more recent decades, since rheumatoid arthritis has been diagnosed with reasonable certainty since about 1940 , and generally accepted criteria for the diagnosis of this disease have only been available since 1958 .

\section{FREQUENCY OF CANCER}

One of the earliest studies of the frequency of cancer in patients with rheumatoid arthritis was an investigation of the major causes of death in a series of 583 patients with rheumatoid arthritis hospitalized at the Massachusetts General Hospital and followed for an average of nearly 10 years. It was of interest that the notable causes of death at that time were valvular heart disease, infection, renal disease, and pulmonary embolism [8]. These data suggested that patients with rheumatoid arthritis had a higher mortality rate than did the general population, due mainly to the fact that younger patients died earlier; the longevity of patients over 50 was not altered. In this group of 583 patients, 130 died and the cause of death was determined (Table I). Cancer accounted for 11.5 percent of the deaths in this selected population of patients with rheumatoid arthritis. The authors compiled the observations of several autopsy series, including their own, and noted that in this accumulated autopsy series of patients with rheumatoid arthritis, cancer was the cause of death in 7 percent of the 191 patients. Interestingly, a later report of autopsy statistics from Finland noted three neoplasms (7 percent) in 41 patients with rheumatoid arthritis in whom the cause of death was determined at autopsy [9].

\section{CLINICAL DATA MEASURING FREQUENCY OF CANCER}

Several reports have assessed the frequency of cancer in patients with rheumatoid arthritis, and these data are shown in Table II. Such studies clearly do not raise a major suspicion that neoplasm frequency in patients with rheumatoid arthritis differs greatly from the general population. In another study of 2,857 patients with rheumatoid arthritis admitted to hospital, an unexpectedly low rate of
TABLE I Causes of Death in Patients with Rheumatoid Arthritis

\begin{tabular}{|c|c|c|c|c|}
\hline \multirow[b]{2}{*}{ Cause } & \multirow[b]{2}{*}{ Number } & \multirow[b]{2}{*}{$\begin{array}{l}\text { Percent } \\
\text { of Total }\end{array}$} & \multicolumn{2}{|c|}{$\begin{array}{l}\text { Autopsied Cases of } \\
\text { Rheumatoid Arthritis } \\
\text { (Combined Series) }\end{array}$} \\
\hline & & & Number & $\begin{array}{l}\text { Percent } \\
\text { of Total }\end{array}$ \\
\hline Cancer & 15 & 11.5 & 14 & 7 \\
\hline Heart disease & 32 & 24.6 & 35 & 19 \\
\hline Infections & 32 & 24.6 & 82 & 41 \\
\hline Nephritis & 17 & 13.0 & 21 & 11.5 \\
\hline $\begin{array}{l}\text { Cardiovascular } \\
\text { accident }\end{array}$ & 12 & 9.2 & 4 & 2 \\
\hline $\begin{array}{l}\text { Gastrointestinal } \\
\text { disease }\end{array}$ & 8 & 6.1 & 11 & 5.5 \\
\hline Pulmonary embolism & 4 & 3.1 & 12 & 7 \\
\hline Accident & 0 & 0 & 1 & 0.5 \\
\hline Miscellaneous & 10 & 7.7 & 11 & 6 \\
\hline Total & 130 & & 191 & \\
\hline
\end{tabular}

Modified from [8].

subsequent neoplasm was noted compared with a large population of patients with benign essential hypertension. studied in a similar manner (Table III) [10]. In summary, these data provide little evidence among United States population groups to suggest major differences in the frequency of cancer in patients known to have rheumatoid arthritis. Furthermore, the distribution of neoplasms appears to reflect the profile seen in the general population. Unfortunately, these studies in general have not been corrected for the relative risks presented by other knowri etiologic agents and, sometimes, have not been corrected for race, sex, or cumulative incidence rates reflecting the real risk of the population groups.

Although the frequency of lymphoma in "garden variety" rheumatoid arthritis does not seem to be clearly increased, recent data suggest that the risk of lymphoma may be increased in those patients with Sjögren's syndrome and rheumatoid arthritis [11]. Among 136 women with sicca syndrome, non-Hodgkin's lymphoma developed in seven from six months to 13 years following initial

TABLE II Frequency of Neoplasms in Patients with Rheumatoid Arthritis

\begin{tabular}{|c|c|c|c|c|c|c|c|}
\hline \multirow[b]{3}{*}{ Reference } & \multirow{3}{*}{$\begin{array}{l}\text { Years of } \\
\text { Follow-up }\end{array}$} & \multicolumn{3}{|c|}{ Control } & \multicolumn{3}{|c|}{ Rheumatold Arthritls } \\
\hline & & \multirow{2}{*}{$\begin{array}{l}\text { Number of } \\
\text { Patients }\end{array}$} & \multicolumn{2}{|c|}{ Neoplasms } & \multirow{2}{*}{$\begin{array}{l}\text { Number of } \\
\text { Patients }\end{array}$} & \multicolumn{2}{|c|}{ Neoplàsms } \\
\hline & & & Number & Percent & & Number & Percent \\
\hline [26] & $>4^{*}$ & 125 & 5 & 4 & 196 & 8 & 4.1 \\
\hline$[17]$ & $4.7-4.9$ & 126 & 9 & 7 & 126 & 9 & 7 \\
\hline
\end{tabular}

${ }^{*}$ Range = one to 288 months.

${ }^{1}$ No explicit data.

‡Believed to be similar to patients with rheumatoid arthritis in whom neoplasms developed. 


\begin{tabular}{|c|c|c|c|c|c|c|c|}
\hline \multirow[b]{3}{*}{ Primary Diagnosis } & \multirow{3}{*}{$\begin{array}{l}\text { Number of } \\
\text { Patients }^{\star}\end{array}$} & \multirow{3}{*}{$\begin{array}{l}\text { Percent } \\
\text { Female }\end{array}$} & & & \multicolumn{3}{|c|}{ Subsequent Neoplasms } \\
\hline & & & \multicolumn{2}{|c|}{ Age } & \multirow[b]{2}{*}{ Number } & \multirow[b]{2}{*}{ Percent } & \multirow{2}{*}{$\begin{array}{c}\text { Statistical } \\
\text { Significance }\end{array}$} \\
\hline & & & Male & Female & & & \\
\hline Benign essential hypertension & 3,295 & 49 & $45.7 \pm 13.4$ & $44.2 \pm 12.7$ & 44 & 1.36 & - \\
\hline Rheumatoid arthritis & 2,867 & 64. & $47.1 \pm 18.2$ & $46.4 \pm 17$ & 17 & 0.59 & $p<0.005$ \\
\hline Discoid lupus erythematosus & 253 & 68 & $42.6 \pm 15.2$ & $39.6 \pm 14.7$ & 4 & 1.58 & $p>0.70$ \\
\hline Systemic lupus erythematosus & 484 & 83 & $38.3 \pm 18.4$ & $33.8 \pm 15.3$ & 18 & 3.72 & $p<0.0005$ \\
\hline
\end{tabular}

*The racial breakdown for the primary diagnosis for whites and blacks, respectively, was: hypertension, 82 and 18 percent; rheumatoid arthritis, 94 and 6 percent; discoid lupus erythematosus, 87 and 13 percent; and systemic lupus erythematosus, 86 and 14 percent.

†Computed by chi-square analysis.

Modified from [10].

assessment, a rate approximately 44 times the incidence expected on the basis of cancer rates prevailing among women of the same age in the general population. The frequency of cancers other than lymphoma was similar to that found among the general population. The risk for patients with the sicca syndrome including rheumatoid arthritis was the same as that for patients having sicca syndrome without rheumatoid arthritis.

\section{STUDIES EVALUATING THE INFLUENCE OF CYTOTOXIC AGENTS ON THE FREQUENCY OF CANCER}

Clinical trials with cyclophosphamide tend to support the concept that this drug suppresses the activity of rheumatoid arthritis, although treatment is frequently accompanied by hemorrhagic cystitis, amenorrhea, alopecia, and gastrointestinal symptoms [12-14]. In a study of 88 patients with active rheumatoid arthritis evaluated by the Cooperating Clinics during a 32-week controlled, doubleblind trial, 75 and $150 \mathrm{mg}$ of cyclophosphamide daily led to improvement of arthritis with few important differences between the two treatment groups [15]. The lower dose was associated with less leukopenia and alopecia. In the

TABLE IV Causes of Death in Patients with Rheumatold Arthritls Treated with Cytotoxic Agents

\begin{tabular}{|c|c|c|c|c|}
\hline \multirow[b]{3}{*}{ Cause of Death } & \multicolumn{4}{|c|}{ Treatment } \\
\hline & \multicolumn{2}{|c|}{$\begin{array}{l}\text { Conventional } \\
(n=141)\end{array}$} & \multicolumn{2}{|c|}{$\begin{array}{l}\text { Cytotoxic Agents } \\
(n=28)\end{array}$} \\
\hline & Number & Percent & Number & Percent \\
\hline Neoplasms & - $^{*}$ & 6 & 8 & 28.5 \\
\hline Infections & - & 29 & 8 & 28.5 \\
\hline Cardiovascular accident & - & 14 & 0 & - \\
\hline Cardiopulmonary disease & - & 28 & 7 & 25 \\
\hline Miscellaneous & - & 23 & 5 & 18 \\
\hline
\end{tabular}

*No explicit data.

Modified from [16]. context of these controlled trials, usually lasting a year or less, which imply that cyclophosphamide is a therapeutically useful agent, it is important to attempt to examine the long-term risk of subsequent neoplasms. Although anecdotal data tend to raise considerable alarm over the possible cancer-inducing influence, few unambiguous controlled data are available.

An early preliminary report focused attention on the possible oncogenic properties of cytotoxic agents used for treatment of rheumatoid arthritis. This showed four to five times the frequency of neoplasms as a cause of death in 28 patients treated with these agents as was seen in 141 patients treated with conventional regimens [16] (Table IV). In the cytotoxic-treated groups, seven of the eight patients with neoplasms had a lymphoproliferative disease.

A group of 126 patients with rheumatoid arthritis admitted to the hospital between the years 1965 to 1974 was treated with cytotoxic drugs and compared with an ageand sex-matched population of patients with rheumatoid arthritis. The follow-up period was approximately five years for each group [17]. The frequency of neoplasms before the study in these patients was five of 126 patients in the control group and seven of 126 in the group subsequently treated with cytotoxic agents. During the follow-up period, each group showed the development of nine neoplasms, including one lymphoma in the control group (Tables $\mathrm{V}$ and $\mathrm{VI}$ ).

\section{DEVELOPMENT OF ACUTE LEUKEMIA IN PATIENTS TREATED WITH CYTOTOXIC AGENTS}

An early report described two patients with rheumatoid arthritis treated with cyclophosphamide in whom acute leukemia developed; both had also been treated with long-term azathioprine. The authors reviewed four additional cases of acute leukemia following cytotoxic drug therapy for rheumatoid arthritis [18]. A subsequent case report suggested that acute myelogenous leukemia developed in a patient with rheumatoid arthritis related to cyclophosphamide treatment (25 mg per day) over a four-year period [19]. Acute myelomonocytic leukemia 
was reported in a patient with rheumatoid arthritis and Sjögren's syndrome following 31 months of cyclophosphamide therapy [20]. It is pertinent to note that this patient had been treated previously with gold, hydroxychloroquine, and methotrexate before initiation of treatment with cyclophosphamide. The authors point out that although patients with Sjögren's syndrome are known to have an increased risk of development of proliferative disorders, particularly reticulum cell sarcoma, acute leukemia is distinctly unusual.

\section{DEVELOPMENT OF CARCINOMA OF THE BLADDER}

In a population of 54 patients treated with cyclophosphamide ( 11 with rheumatoid arthritis, 43 with systemic lupus erythematosus), two cases of bladder carcinoma were reported: one in each disease group [21]. Bladder carcinoma developed 28 to 60 months after withdrawal of the drug; one of the two victims smoked cigarettes. Since the expected number of cases of bladder carcinoma based on the age incidence for that locale was 0.02 for the period of observation, and the actual number of cases was two of 54 patients, the relative risk ratio was thought to be approximately 100 . Carcinoma of the bladder was also reported in a 75-year-old woman (a nonsmoker) treated with a maximum of $50 \mathrm{mg}$ per day of cyclophosphamide over a period of about 12 years [22].

\section{DATA DERIVED FROM CANCER CHEMOTHERAPY}

Cancer chemotherapists have become concerned over the likelihood of development of a second neoplasm as a complication of cancer chemotherapy. A review of this problem points out that alkylating agents used to treat ovarian cancer, Hodgkin's disease, and as an adjuvant in the treatment of breast cancer have been associated with apparent excess development of acute leukemia [23]. The data appear to indicate that, in humans, a four-year latent period may be expected from the initiation of drug exposure until the appearance of the second neoplasm.

Difficulties inherent in interpreting this sort of data may be appreciated by considering one of these studies [24]. In this study, the leukemogenic potential of alkylating agents used for the treatment of patients with advanced ovarian cancer was examined. Thirteen cases of acute nonlymphocytic leukemia occurred among 5,455 patients compared with the 0.62 cases expected, yielding a relative risk of approximately 21 . Although all 13 patients in whom leukemia developed received alkylating agents, nine had also received radiotherapy. The authors referred to another study involving over 13,000 patients with ovarian cancer in which no excess of leukemia was noted, even among a large number who also received radiation. Consequently, although the excess may be attributable to alkylating agents, it is difficult to exclude the possibility that these effects were magnified by exposure to radiation.
TABLE V Cytotoxic Drugs and Neoplasms in Patients with Rheumatoid Arthritis

\begin{tabular}{|c|c|c|c|}
\hline & \multirow[b]{2}{*}{ Number } & \multicolumn{2}{|c|}{ Neoplasms } \\
\hline & & Before Study & During Study \\
\hline $\begin{array}{l}\text { Age-sex matched } \\
\text { rheumatoid arthritis } \\
\text { control group } \\
\text { Cytotoxic-treated } \\
\text { rheumatoid arthritis } \\
\text { group }\end{array}$ & 126 & 5 & 9 \\
\hline \multicolumn{4}{|c|}{$\begin{array}{l}\text { Follow-up }=4.7 \text { to } 4.9 \text { years. } \\
{ }^{*} \text { Cytotoxic drugs }=\text { cyclophosphamide and/or nitrogen mustard } \\
\text { (105), remainder received one or both with chlorambucil, thiotepa, } \\
\text { methotrexate, or azathioprene. } \\
\text { From [17]. }\end{array}$} \\
\hline \multicolumn{4}{|c|}{$\begin{array}{ll}\text { TABLE VI } & \text { Types of Neoplasms in Patients with } \\
\text { Rheumatoid Arthritis }\end{array}$} \\
\hline Type of Cancer & Control Subjects & Cytotoxic & eated Patients \\
\hline Basal cell carcinoma & 3 & & 4 \\
\hline Breast & 3 & & - \\
\hline Lung & 1 & & 3 \\
\hline Carcinomatosis & 1 & & 1 \\
\hline Lymphoma & 1 & & - \\
\hline Gastric & - & & 1 \\
\hline
\end{tabular}

Modified from [17].

A nine-fold increase in bladder cancer was found in patients who were treated with cyclophosphamide for an initial non-uroepithelial cancer [25]. Among 19,082 patients examined who survived the non-uroepithelial cancer for at least five years, bladder cancer, as a second neoplasm, developed in 42 . In terms of treatment, 170 patients had been treated with cyclophosphamide for their primary neoplasm, and among this group, bladder cancer, as a second neoplasm, developed in three (1.8 percent), whereas only 39 patients, among the 18,912 not treated with cyclophosphamide, had bladder cancer $(0.21$ percent). Interestingly, the three patients in whom bladder cancer developed following cyclophosphamide therapy were, in fact, long-term survivors of non-urologic cancers and, in addition, had a long cigarette-smoking history. Two had received substantial doses of abdominal/pelvic radiation in the treatment of their first tumor. Clearly, it is difficult to interpret such data in an unambiguous fashion.

\section{COMMENTS}

Review of the data in the United States related to the frequency of neoplasms in rheumatoid arthritis subsets of the population and possible oncogenic effects of cytotoxic drug therapy used for rheumatoid arthritis does not encourage very firm conclusions. Available data do not 
make a case for an unusual cancer incidence in patients with rheumatoid arthritis. This is further weakened by recognition that available data are meager and flawed by inclusion of uncontrolled variables discussed earlier. Concern over possible cyclophosphamide induction of bladder cancer and acute leukemia promoted by alkylating agents is justified. This is not to say that these relationships are proved beyond reasonable doubt or that the magnitude of the risk has been quantified. Definitive data will probably require an extended longitudinal study of a very large group of patients in order to permit adequate stratification and control of complicating variables.
Aggressive, mutilating, incapacitating rheumatoid arthritis, uncontrolled by conventional therapy, presents its own set of risks. Many patients and physicians may conclude that the personal consequences of uncontrolled rheumatoid arthritis outweigh the additional risks that may be inherent in cytotoxic therapy. Clearly, patients must understand this "balance of risks" before accepting cytotoxic therapy for rheumatoid arthritis.

\section{ACKNOWLEDGMENT}

We are pleased to thank Mrs. Barbara King for her expert assistance in the preparation of this manuscript.

\section{REFERENCES}

1. Walker SE, Anver MR: Accelerated appearance of neoplasms in female NZB/NZW mice treated with high-dose cyclophosphamide. Arthritis Rheum 1979; 22: 1338.

2. Theofilopoulos AN, Dixon FJ: Immune complexes in human disease. Review article. Am J Pathol 1980; 100: 550.

3. Inman RD, Day NK: Immunologic and clinical aspects of immune complex disease. Am J Med 1981; 70: 1097.

4. Bradley JD, Pinais RS: Carcinoma polyarthritis: role of immune complexes in pathogenesis. J Rheumatol 1983; 10: 826 .

5. Young JL, Pollack ES: The incidence of cancer in the United States. In: Schottenfeld D, Fraumeni JF, eds. Cancer epidemiology and prevention. Philadelphia: WB Saunders, 1982; 138.

6. Greene $\mathrm{MH}$ : Non-Hodgkin's lymphoma and mycosis fungoides. In: Schottenield D, Fraumeni JF, eds. Cancer epidemiology and prevention. Philadelphla: WB Saunders, 1982; 754.

7. Petrakis NL, Ernster VL, King M-C: Breast. In: Schottenfeld D, Fraumeni JF, eds. Cancer epidemiology and prevention. Philadelphia: WB Saunders, 1982; 855.

8. Cobb S, Anderson F, Bauer W: Length of life and cause of death in rheumatoid arthritis. N Engl J Med 1953; 249: 553

9. Mutru $\mathrm{O}$, Isomaki $\mathrm{H}$ : Causes of death in autopsied rheumatoid arthritis patients. Scand J Rheum 1976; 5: 239.

10. Lewis RB, Castor CW, Knisley RE, Bole GG: Frequency of neoplasia in systemic lupus erythematosus and rheumatoid arthritis. Arthritis Rheum 1976; 19: 1256.

11. Kassan SS, Thomas TL, Moutsopoulos HM, et al: Increased risk of Iymphoma in Sicca syndrome. Ann Intern Med 1978; 89: 888

12. Fosdick WM, Parsons, JL, Hill DF: Long-term cyclophosphamide therapy in rheumatoid arthritis. Arthritis Rheum 1968; 11: 151 .

13. Cooperating Clinics Committee of the American Rheumatism Association: A controlled trial of cyclophosphamide in theumatoid arthritis. N Engl J Med 1970; 283: 883

14. Townes AS, Sowa JM, Shulman LE: Controlled trial of cyclophosphamide in theumatoid arthritis. Arthritis Rheum 1976; 19: 563.
15. Williams HJ, Reading JC, Ward Jr, O'Brien WM: Comparison of high and low dose cyclophosphamide therapy in rheurnatoid arthritis. Arthritis Rheum 1980; 23: 521.

16. Parsons JL, Strong FS, Fosdick WM: The causes of death in patients with rheumatoid arthritis treated with cytotoxic agents (abstr). J Rheumatol 1974; 1: 75.

17. Kirsner $A B$, Farber SJ, Sheon RP, Finkel RI: The incidence of malignant disease in patients receiving cytotoxic therapy for rheumatoid arthritis. Ann Rheum Dis 1982; 41 (suppl): 32.

18. Seidenfeld AM, Smythe HA, Ogryzlo MA, Urowitz MB, Dotten DA: Acute leukemia in rheumatoid arthritis treated with cytotoxic agents. J Rheumatol 1976; 3: 295.

19. Kapadia SB, Kaplan SS: Acute myelogenous leukemia following immunosuppressive therapy for rheumatoid arthritis. Am $\mathrm{J}$ Clin Pathol 1978; 70: 301.

20. Hochberg MC, Shulman LE: Acute leukemia following cyclophosphamide therapy for Sjogren's syndrome. Johns Hopkins Med J 1978; 142: 211.

21. Plotz $\mathrm{PH}$, Klippel JH, Decker JL, et al: Bladder complications in patients receiving cyclophosphamide for systemic lupus erythematosus or rheumatoid arthritis. Ann Intern Med 1979; 91 : 221.

22. Ansher AF, Melton JW III, Sliwinski AJ: Bladder malignancy in a patient receiving low dose cyclophosphamide for treatment of rheumatoid arthritis. Arthritis Rheum 1983; $26: 804$.

23. Chabner BA: Second neoplasm-a complication of cancer chemotherapy. N Engl J Med 1977; 297: 213.

24. Reimer RR, Hoover R, Fraumeni JF, Young RC: Acute leukemia after alkylating-agent therapy of ovarian cancer. $\mathrm{N}$ Engl J Med $1977 ; 297 ; 177$.

25. Fairchild WV, Spence CR, Solomon HD, Gangai MP: The incidence of bladder cancer after cyclophosphamide therapy. $\mathrm{J}$ Urol 1979; 122: 163.

26. Owen DS Jr, Waller M, Toone E: Rheumatoid disease and malignancy. Arthritis Rheum 1967; 10: 302 .

27. Ragan C, Snyder Al: Rheumatoid arthritis. DM 1955; November: 1 . 